\title{
SPECTROSCOPIC INVESTIGATIONS OF GALACTIC CLUSTERS WITH ASSOCIATED CEPHEID VARIABLES. IV. COLLINDER 220 AND UW CAR
}

\author{
I. A. Usenko, ${ }^{1,2}$ A. Yu. Kniazev ${ }^{3,4}$ I. Yu. Katkov,${ }^{5}$ V. V. Kovtyukh, ${ }^{1}$ \\ T. V. Mishenina, ${ }^{1}$ A. S. Miroshnichenko, ${ }^{6,7,8}$ D. G. Turner ${ }^{9}$ \\ 1 Astronomical Observatory, Odessa National University, Shevchenko Park, \\ Odessa 65014, Ukraine,vkovtyukh@ukr.net \\ 2 Mykolaiv Astronomical Observatory, Obsevatorna 1, Mykolaiv 54030, Ukraine, \\ igus99@ukr.net \\ 3 South African Astronomical Observatory, P.O. 7925, Cape Town, \\ South Africa, akniazev@saao.ac.za \\ ${ }^{4}$ Southern African Large Telescope Foundation, P.O. 7925, Cape Town, \\ South Africa \\ ${ }^{5}$ New York University, Abu Dhabi, Saadiyat Island, P.O. 129188 \\ Abu Dhabi, UAE, ik52@nyu.edu \\ ${ }^{6}$ Dept. of Physics and Astronomy, University of North Carolina at \\ Greensboro, P.O.Box 261170, Greensboro, NC 27402, USA, a_mirosh@uncg.edu \\ 7 Main Astronomical Observatory of the Russian Academy of Sciences, \\ Pulkovskoe shosse 65-1, Saint-Petersburg, 196140, Russia \\ ${ }^{8}$ Fesenkov Astrophysical Institute, Observatory 23, Almaty, 50020, Kazakhstan \\ ${ }^{9}$ Dept. of Astronomy and Physics, Saint Mary's University, \\ 923 Robie Street, Halifax B3H3C3, Nova Scotia, Canada, turner@ap.smu.ca
}

ABSTRACT. We present the results of a spectroscopic and photometric investigation of 18 probable members of the open cluster Collinder 220, which contains the Cepheid UW Car. Besides the Cepheid, we studied tree K-giants, two B-giants, and twelve B-A-F main sequence stars. Radial velocities (RV), $\mathrm{v} \sin \mathrm{i}, T_{\text {eff }}$, and $\log \mathrm{g}$ were determined using spectroscopic model fitting and atmosphere models. We have derived color-excesses, reddenings, and intrinsic colors for these stars using their $T_{\text {eff }}$ and $\log g$ from comparison to the atmosphere models, especially for hot stars. Proper motions, RV, and the GAIA DR2 2018 parallaxes allowed us to determine their membership in the cluster and absolute magnitudes. We found that seven stars along with the Cepheid can be the cluster members with a high confidence. The parallaxes and reddenings of the 7 confident cluster members led to the distances in a range of 1900-2800 pc, while the other stars are probably foreground objects. All the members have $[\mathrm{Fe} / \mathrm{H}]$ near 0.1 dex. The B-giant HD 90435 located near the cluster's "turn-off" point has a low projected rotational velocity, and this fact allows us to determine its chemical composition to compare with that of the Cepheid UW Car. The CNO abundances of HD 90435 are nearly solar, while the Cepheid shows a deficit of carbon, an overabundance of nitrogen, a nearly solar oxygen, and an overabundance of sodium. The confident cluster member, K-supergiant CPD $-57^{\circ} 3199$, has CNO- and $\mathrm{Na}$ abundances close to those of UW Car.

Key words: Open clusters: radial velocities; Stars: abundance; GAIA parallaxes; Cepheids; B - giants; K-giants; individual: Collinder 220, UW Car, CPD $-57^{\circ} 3199$, HD 90435, HD 90552, HD 302751, HD 302759, HD 302760, HD 302761, HD 302858, TYC 8608-1-1, TYC 8608-25-1, TYC 8608-33-1, TYC 8608-69-1, TYC 8608-153-1, TYC 8608-193-1, TYC 8608-213-1, TYC 8608-221-1, TYC 8608-1503-1.

АНОТАЦЯ. Ми презентуємо результати фотометрічних та спектроскопічних досліджень 18-ти вірогідних членів розсіяного скупчення Collinder 220, яке включає цефеїду UW Car. Окрім цефеїди, ми дослідили три К-гиганта, два В-гіганта та дванадцять В-A-F- зір головної послідовності. Радіальні швидкості RV, та параметри v sin i, $T_{\text {eff }}$ та 
$\log$ g були отримані задяки використанню фіттінгу спектроскопічних моделей та моделей атмосфер. Ми вивели надлишки кольору, почервоніння, та справжні кольори для цих зір, використовуючи ïx $T_{\text {eff }}$ та $\log g$ шляхом порівняння 3 моделями атмофер, особливо для гарячих зір. Власний pyx, RV та паралакси з каталогу GAIA DR18 дозволяють встановити їх членство у скупченні та їх абсолютні магнітуди. Ми встановили, що сім зір 3 цефеїдою з високою вірогідністю можуть бути членами скупчення. Паралакси та почервоніння сімох надійних членів скупчення надають відстані у рамках 1900-2800 пс, тоді як інші зорі вірогідно є об'єктами переднього плану. Усі ці об'єкти мають $[\mathrm{Fe} / \mathrm{H}]=0.1$ dex. В-гігант $\mathrm{HD} 90435$, який міститься біля "точки повороту" скупчення, має низьку проєкцію швидкості обертання, цей факт дозволяе отримати його хімічний склад, щоб порівняти з аналогічним у цефеїди UW Car. Вміст CNO у HD 90435 близький до сонячного, тоді як цефеїда показує дефіціт вуглецю, надлишок азоту, близький до сонячного вмист кисню та надлишок натрію. Дійсний член скупчення, K-надгігант CPD $-57^{\circ} 3199$ має вміст CNO та Na близький до вмісту y UW Car.

Ключові слова: Розсіяні скупчення: променеві швидкості; Зорі: хімічний склад; паралакси GAIA; Класичні цефеїди; В-гіганти; К-гіганти; індивідуально: Collinder 220, UW Car, CPD $-57^{\circ} 3199$, HD 90435, HD 90552, HD 302751, HD 302759, HD 302760, HD 302761, HD 302858, TYC 8608-1-1, TYC 8608-25-1, TYC 8608-33-1, TYC 8608-69-1, TYC 8608-153-1, TYC 8608-193-1, TYC 8608-213-1, TYC 8608-221-1, TYC 8608-1503-1.

\section{Introduction}

Collinder 220 is a rather poorly investigated open cluster. It contains 41 stars fainter than 10-mag of mostly $B$ - and $A$ - spectral types. Besides, it contains a $5 .{ }^{d} 35$ Cepheid UW Car as a possible member. According to Segel et al. (2019), the earliest spectral type stars in it are B7-B8, $\left.E_{(} B-V\right)=0 .{ }^{m} 25 \pm 0 .{ }^{m} 01$, the age near $370 \mathrm{Myr}$, and the metallicity $[\mathrm{Fe} / \mathrm{H}]=$ 0.00 dex. Nevertheless there are some discrepancies between the distance moduli derived by different studies. In particular, $\mathrm{V}_{0}-\mathrm{M}_{V}=11 \cdot{ }^{m} 99 \pm 0 .{ }^{m} 20$ (Segel et al. 2019), $11 .^{m} 48 \pm 0 .^{m} 24$ (Chen 2015) and $10 .^{m} 83$ (Dias et al. 2014). If the ratio of the total to selective extinction $\mathrm{R}=\mathrm{A}_{V} / \mathrm{E}_{B-V}=3 .^{m} 34 \pm 0 .^{m} 02$, we can assume that $\mathrm{A}_{V}=0 \cdot^{m} 84 \pm 0 .^{m} 02$ for the color-excess from Segel et al. (2019). This way the following distances, $1698 \pm 164,1342 \pm 157$, and 995 pc have been derived, respectively. According to Cantat-Granden et al. (2018) (GAIA catalog), the distance to the cluster is $\sim 2543 \mathrm{pc}$.
Kharchenko et al. (2013) gave $\langle\mathrm{RV}\rangle=-13.0 \pm 0.2$ $\mathrm{km} \mathrm{s}^{-1}$ for the cluster, while $\langle\mathrm{RV}\rangle=-12.19 \pm 0.12$ $\mathrm{km} \mathrm{s}^{-1}$ according to the GAIA DR18 catalogue. Collinder 220 has not been carefully studied spectroscopically except for UW Car (Luck \& Lambert 2011). Therefore, the main goals of our investigation are as follows:

1) to measure the radial and rotational velocities of the cluster's stars, 2) to determine the atmospheric parameters, metallicities, $\mathrm{CNO}$ and $\mathrm{Na}$ abundances and compare the abundances of the objects of different spectral types, 3) to determine the distances using GAIA DR2 parallaxes and RV data, and to check their membership in the cluster.

\section{Observations}

Our observations were taken at the $11 \mathrm{~m}$ SALT (Southern African Large Telescope) equipped with HRS (High Resolution Spectrograph). HRS is a dualbeam (3700-5500 \& 5500-8900 ̊) fiber-fed, whitepupil, échelle spectrograph, which uses VHP gratings as cross dispersers. We obtained one spectrum for each object using the medium mode with the spectral resolving power $R=40000$ and an average $\mathrm{S} / \mathrm{N}$ over 100 , which are sufficient to reach the goals of our study. These spectra have been used to derive the atmosphere parameters and chemical abundances for some elements of the open cluster members. The data were reduced using the échelle context in MIDAS. Also, the feros package developed for échelle data reduction from the Fiber-fed Extended Range Optical Spectrograph (FEROS) was used. Both FEROS and HRS provide very similar results.

We used the DECH30 package $^{1}$ designed to use the spectra in FITS format to measure the line depths and equivalent widths. The radial and rotational velocities were measured by fitting of the observed spectra with models from Coelho (2014). The object IDs, magnitudes, spectral types, proper motions, parallaxes from the GAIA DR18 catalogue, measured radial and rotational velocities for each spectrum are given in Table 1.

\section{Results and Analysis}

3.1 Radial and rotational velocities, proper motions and parallaxes

Distances derived from the Segel et al. (2019) and Cantat-Granden et al. (2018) data determine one of the main criteria for membership in the open cluster: a parallax range from 0.59 to 0.39 mas. According to Table 1, judging from the proper motion, radial velocity, and parallax measurements, seven objects are

\footnotetext{
${ }^{1}$ http://gazinur.com/DECH-software.html
} 
Table 1: General data for the observed objects in Collinder 220 and derived RVs.

\begin{tabular}{|c|c|c|c|c|c|c|c|}
\hline Object & $V$ & Sp.type & $\mu_{\alpha}$ & $\mu_{\delta}$ & $R V, \mathrm{~km} \mathrm{~s}^{-1}$ & $\mathrm{v} \sin \mathrm{i}, \mathrm{kms}^{-1}$ & PLX (GAIA) \\
\hline $\mathrm{UW} \mathrm{Car}^{1}$ & 9.47 & G0 Ib & -7.305 & +3.590 & $+17.11 \pm 0.04$ & $36.6 \pm 0.1$ & $0.2631 \pm 0.0290$ \\
\hline $\mathrm{CPD}-57^{\circ} 3199$ & 10.86 & & -7.328 & +2.680 & $+18.76 \pm 0.43$ & $0.2 \pm 0.5$ & $0.3463 \pm 0.0286$ \\
\hline HD 90435 & 8.88 & B7/8III/IV & -7.761 & +3.658 & $+9.51 \pm 0.23$ & $21.0 \pm 0.1$ & $0.5164 \pm 0.0465$ \\
\hline HD 90552 & 9.82 & $\mathrm{~A} 4 / 7$ & -15.592 & +4.086 & $+30.24 \pm 0.12$ & $130.0 \pm 0.4$ & $1.0433 \pm 0.0606$ \\
\hline HD 302751 & 10.15 & K2 & -11.823 & +8.164 & $+3.57 \pm 0.24$ & $0.6 \pm 0.4$ & $0.9386 \pm 0.0296$ \\
\hline HD 302759 & 11.00 & A & -9.162 & +4.149 & $+9.35 \pm 0.25$ & $54.0 \pm 0.4$ & $0.5947 \pm 0.0332$ \\
\hline HD 302760 & 11.00 & A3 & -2.414 & +0.091 & $-2.72 \pm 0.02$ & $21.3 \pm 0.1$ & $0.8590 \pm 0.0328$ \\
\hline HD 302761 & 10.28 & $\mathrm{~F} 2$ & -9.068 & +3.600 & $+5.76 \pm 0.19$ & $68.6 \pm 0.2$ & $1.9200 \pm 0.2500$ \\
\hline HD 302858 & 11.46 & A0 & -6.330 & +2.781 & $-0.78 \pm 1.10$ & $174.0 \pm 0.4$ & $0.6726 \pm 0.0381$ \\
\hline TYC 8608-1-1 & 12.01 & & -8.612 & +1.721 & $+4.84 \pm 0.24$ & $39.9 \pm 0.2$ & $0.3996 \pm 0.0299$ \\
\hline TYC 8608-25-1 & 12.49 & & -8.321 & +1.287 & $-4.40 \pm 0.09$ & $149.6 \pm 0.1$ & $0.4438 \pm 0.0290$ \\
\hline TYC 8608-33-1 & 12.10 & & -0.5 & +3.3 & $+11.45 \pm 0.31$ & $46.3 \pm 0.2$ & \\
\hline TYC 8608-69-1 & 11.92 & & -7.706 & +3.257 & $+8.77 \pm 0.18$ & $34.3 \pm 0.2$ & $0.3548 \pm 0.0279$ \\
\hline TYC 8608-153-1 & 11.59 & & -7.844 & +2.164 & $+10.99 \pm 0.13$ & $149.4 \pm 1.1$ & $1.0902 \pm 0.0305$ \\
\hline TYC 8608-193-1 & 10.87 & & -7.291 & +3.146 & $-44.24 \pm 0.04$ & $0.0 \pm 0.1$ & $0.4448 \pm 0.0292$ \\
\hline TYC 8608-213-1 & 12.30 & & -6.243 & +5.414 & $+27.50 \pm 0.32$ & $62.7 \pm 0.1$ & $0.5156 \pm 0.0293$ \\
\hline TYC 8608-221-1 & 10.66 & & -11.166 & -1.933 & $-46.78 \pm 0.04$ & $0.1 \pm 0.2$ & $0.7723 \pm 0.0327$ \\
\hline TYC 8608-1503-1 & 12.04 & & -7.572 & +3.532 & $-7.61 \pm 0.02$ & $34.1 \pm 0.4$ & $0.3832 \pm 0.0323$ \\
\hline
\end{tabular}

1 - Phase 0. ${ }^{P} 761$ according to ASAS SN (Kochanek et al. 2017)

most likely foreground stars, and three others have an uncertain status.

It should be noted that our results are consistent with those from other sources: $R V=-13.00 \mathrm{~km} \mathrm{~s}^{-1}$ (Mermilliod et al. 2008) and $-12.19 \pm 0.13$ (GAIA DR2) for CPD $-57^{\circ} 3199 ; R V=1.17 \pm 0.19 \mathrm{~km} \mathrm{~s}^{-1}$ (GAIA DR2) for HD 302751 and $R V=41.45 \pm 0.50$ (GAIA DR2) for TYC 8608-221-1, respectively. It is obvious that the majority of the confident cluster members have close $R V \mathrm{~s}$. As seen, these objects $R V \mathrm{~s}$ lie in the range from -7.0 to $+19.0 \mathrm{~km} \mathrm{~s}^{-1}$. As for UW Car, besides our estimate, there are two other estimates of the $R V=$ $-14.80 \pm 0.9 \mathrm{~km} \mathrm{~s}^{-1}$ (Gontcharov 2006) and -1.08 \pm 14.14 $\mathrm{km} \mathrm{s}^{-1}$ (GAIA DR2).

As seen in Table 1, three K-giants CPD $-57^{\circ} 3199$, HD 302751, and TYC 8608-221-1 as well as the A-star TYC 8608-193-1 have evidently low v sin i, the B-giant HD 90435 and the A-star HD 302760 have relatively low vsin i, while other hot main-sequence (hereafter MS) stars are faster-rotating objects. It was very surprising to detect that the Cepheid UW Car has an unusually high $\mathrm{v} \sin \mathrm{i}$.

3.2 Color-indices, color-excesses, reddenings, and atmospheric parameters

As was mentioned above, only Segel et al. (2019) determined a color-excess for the cluster. It corresponds to a visual extinction of $\mathrm{A}_{V}=0 .{ }^{m} 84 \pm 0 .{ }^{m} 02$. To improve these parameters, we have used their $T_{\text {eff }}$ and $\log \mathrm{g}$ determined with the model fitting method. In the next step, the intrinsic color-indices $(\mathrm{B}-\mathrm{V})_{0}$ were determined for the hot B- and A-type stars using the Kurucz
(1993) models and theoretical color-indices from Bessel et al. (1998). For more evolved stars of FGK spectral types with a large number of narrow metallic absorption lines we used the lines depth relationships to derive $T_{\text {eff }}$ (Kovtyukh 2007) and a Fe ionization balance to derive $\log g$. These estimates give us an opportunity to determine corresponding $(\mathrm{B}-\mathrm{V})_{0}$ for the $F G K$-stars.

Figure 1 demonstrates a "vsin i- $T_{\text {eff" }}$ graph for the studied stars. As seen, the three $K$ - giants, the Cepheid, the F- and A- MS-stars (12 objects) have a notable relation, while the hot giants group ( 6 objects) are located separately. This graph allows to separate stars of the different luminosity types in this cluster.

The described above results allowed us to determine the color-excesses, reddenings, and interstellar extinction. All these data are given in Table 2. We used the (B-V) color-indices from TYCHO catalogue (Høg et al. 2000). Fig. 2 represents the reddening versus intrinsic color diagram for the cluster. There are two groups of hot stars: the first group ( 7 objects) has reddening values in a range of $0 .^{m} 00-0 .{ }^{m} 34$ with a mean $\mathrm{A}_{V}=0 .{ }^{m} 20 \pm 0 .{ }^{m} 11$, while that for the second group is $0 .^{m} 86-1 .^{m} 41$ and a mean $\mathrm{A}_{V}=1 .^{m} 02 \pm 0 .{ }^{m} 32$, respectively. The first group most likely consists of the confident cluster members (according to their parallaxes), and the second one consists of possible foreground objects. It is interesting that the possible foreground objects HD 90552 and HD 302760 fit well into the first group. TYC 8608-193-1, whose $R V$ estimate differs noticeably from those of the other group, behaves similarly, while another possible foreground object TYC 8508-1-153 seems to belong to the second group. The reddening value $\mathrm{A}_{V}=0 \cdot^{m} 84 \pm 0 .^{m} 02$ for the cluster derived from the color-excess suggested 


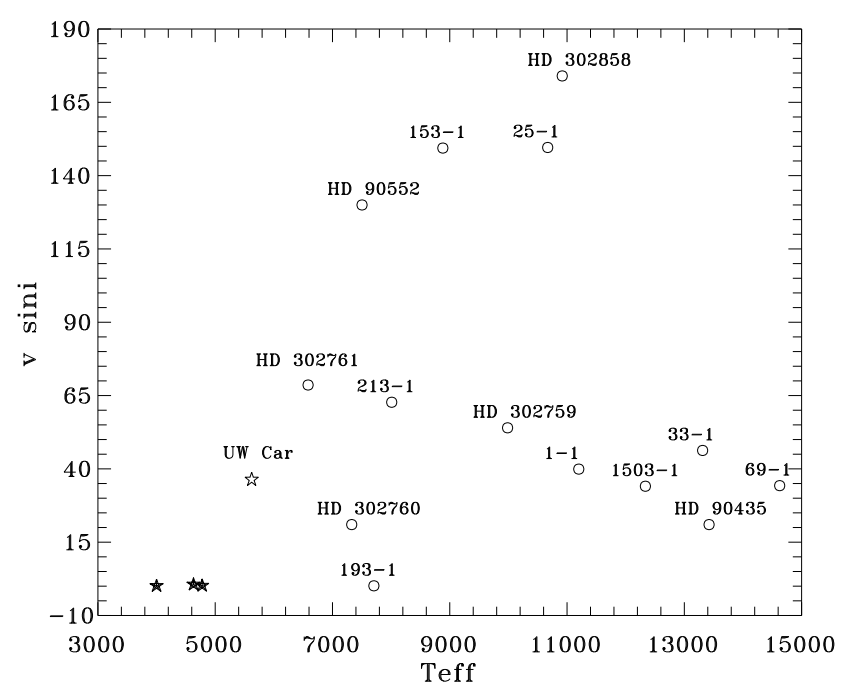

Figure 1: Relationship between the rotation velocity and $T_{\text {eff }}$ for the objects from our list. Open circles show the main sequence B- and A- stars and B-giants, filled five-point stars show the K-supergiants, open fivepoint stars show the Cepheid.

by Siegel et al. (2019) is closer to that of the second group, and the same we can say about the $\mathrm{A}_{V}$ for the Cepheid UW Car. The average $A_{V}$ for both groups comes to $0 .^{m} 65 \pm 0 .{ }^{m} 18$.

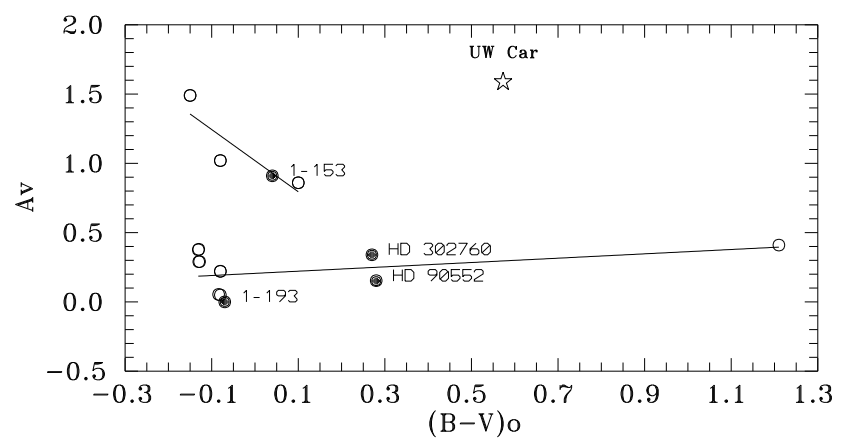

Figure 2: Reddening versus intrinsic color diagram for probable Collinder 220 members. Open circles represent probable confident members, filled circles show probable foreground objects, lines - linear approximations. Open star - Cepheid UW Car.

\subsection{Absolute magnitudes and distances}

Table 3 contains the absolute magnitudes of the Collinder 220 objects derived from the GAIA DR2 parallaxes and our $T_{\text {eff }}$ and $A_{V}$ data as well as from the (B-V $)_{0}$ color-indices and $T_{\text {eff }}$ from to the Pecaut \& Mamajek (2013) tables for MS stars. According to Table 3, the absolute magnitude and distance, which were calculated by these two methods show an acceptable close range values only for three objects. Figure 3 represents the HR-diagram for the Collinder 220 objects. It shows that all the possible confident cluster members except for TYC 8608-193-1 lie well on the MS. TYC 860869-1 is located near the cluster's turn-off point, and it could probably be a blue giant. HD 90435 has already passed this point and is indeed a blue giant. It is interesting that possible foreground stars HD 302858 and TYC 8608-153-1 fall onto the cluster's MS. HD 90662, HD 302760, and TYC 8608-193-1 are not the cluster's members.

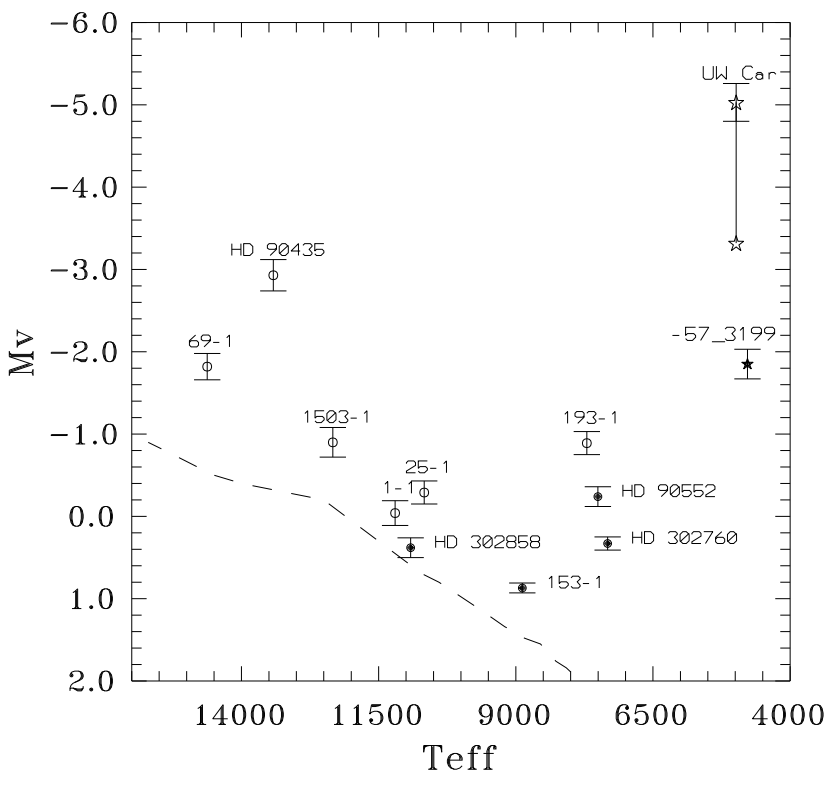

Figure 3: $T_{\text {eff }}$ versus $\mathrm{M}_{V}$ diagram for the Collinder 220 possible members. The symbols represent the same objects as in Fig. 2., and filled star - K-giant $\mathrm{CPD}-57^{\circ} 3199$. For UW Car $\mathrm{M}_{V}$ data accodring to GAIA DR18 parallax (with error bars) and Fernie et al. (1995) catalogue. Dashed line - main sequence according to Pecaut \& Mamajek (2013).

Figure 4 represents a $\mathrm{E}_{B-V}$ versus $\left(\mathrm{V}-\mathrm{M}_{V}\right)$ variable - extinction diagram for the possible confident members of Collinder 220. This diagram shows that the distance modulus for the open cluster is 11. ${ }^{m} 83 \pm 0 .{ }^{m} 71$. Therefore, taken into account our reddening estimates of $0 .^{m} 20$ and $1 .^{m} 02$ we can derive the Collinder 220 distances of $2118 \pm 590$ or $1452 \pm 405$ $\mathrm{pc}$, respectively. The former value takes into account the Cepheid UW Car, which belongs to the cluster, is more preferable. However, the intermediate value is closer to the color-excess and distance modulus from Segel et al. (2019), as mentioned above. 
Table 2: Atmospheric parameters, rotational velocities, intrinsic colors, color-excesses, reddenings, and interstellar extinctions for the Collinder 220 objects.

\begin{tabular}{|l|r|r|r|r|r|c|}
\hline Star & $T_{\text {eff }}$ & $\log \mathrm{g}$ & $(\mathrm{B}-\mathrm{V})_{0}$ & $\mathrm{E}_{B-V}$ & $\mathrm{~A}_{V}$ & $R$ \\
\hline UW Car & $4984 \pm 3$ & $2.52 \pm 0.01$ & 0.57 & 0.46 & 1.56 & 3.51 \\
CPD -57 3199 & $4855 \pm 3$ & $1.79 \pm 0.01$ & 1.21 & 0.11 & 0.41 & 3.72 \\
HD 90435 & $13420 \pm 2$ & $3.76 \pm 0.01$ & -0.13 & 0.11 & 0.38 & 3.30 \\
HD 90552 & $7504 \pm 5$ & $3.43 \pm 0.01$ & 0.28 & 0.05 & 0.15 & 3.39 \\
HD 302751 & $4630 \pm 3$ & $2.01 \pm 0.01$ & - & - & - & - \\
HD 302759 & $9985 \pm 6$ & $3.29 \pm 0.00$ & -0.06 & 2.95 & - & - \\
HD 302760 & $7327 \pm 6$ & $2.47 \pm 0.03$ & 0.27 & 0.10 & 0.34 & 3.40 \\
HD 302761 & $6503 \pm 3$ & $2.41 \pm 0.01$ & - & - & - & - \\
HD 302858 & $10917 \pm 4$ & $3.92 \pm 0.01$ & -0.08 & 0.07 & 0.22 & 3.40 \\
TYC 8608-1-1 & $11200 \pm 10$ & $3.84 \pm 0.01$ & -0.08 & 0.02 & 0.05 & 3.35 \\
TYC 8608-25-1 & $10669 \pm 0$ & $3.43 \pm 0.00$ & -0.08 & 0.30 & 1.02 & 3.36 \\
TYC 8608-33-1 & $13331 \pm 7$ & $3.84 \pm 0.01$ & -0.13 & 0.09 & 0.29 & 3.30 \\
TYC 8608-69-1 & $14626 \pm 6$ & $3.32 \pm 0.01$ & -0.15 & 0.46 & 1.49 & 3.31 \\
TYC 8608-153-1 & $8882 \pm 14$ & $3.77 \pm 0.02$ & 0.04 & 0.27 & 0.91 & 3.37 \\
TYC 8608-193-1 & $7705 \pm 5$ & $3.50 \pm 0.01$ & -0.07 & 0.01 & 0.00 & 3.36 \\
TYC 8608-213-1 & $8010 \pm 1$ & $3.52 \pm 0.01$ & 0.15 & - & - & - \\
TYC 8608-221-1 & $4000 \pm 3$ & $2.25 \pm 0.01$ & - & - & - & - \\
TYC 8608-1503-1 & $12336 \pm 27$ & $4.22 \pm 0.01$ & 0.10 & 0.26 & 0.86 & 3.32 \\
\hline
\end{tabular}

$1-T_{\text {eff }}, \log \mathrm{g}$, and $(\mathrm{B}-\mathrm{V})_{0}$ for the pulsational phase of 0.761 according to Kochanek et al. (2017).

Table 3: Comparison between absolute magnitudes and distances, determined using the GAIA DR2 parallaxes and photometric data.

\begin{tabular}{|l|c|c|c|r|r|}
\hline Object & $\mathrm{M}_{V}$ (GAIA) & $\mathrm{M}_{V}$ (P\&M13) & $\mathrm{d}$ (pc) (GAIA) & $\mathrm{d}$ (pc) (P\&M13) & Membership \\
\hline UW Car & $-5.03 \pm 0.23$ & & $3776 \pm 422$ & $\mathrm{~m}$ \\
CPD -57 3199 & $-1.85 \pm 0.18$ & & $2888 \pm 239$ & & $\mathrm{~m}$ \\
HD 90435 & $-2.93 \pm 0.19$ & -0.32 & $1937 \pm 174$ & 582 & $\mathrm{~m}$ \\
HD 90552 & $-0.24 \pm 0.12$ & +2.29 & $959 \pm 56$ & 299 & $\mathrm{fg}$ \\
HD 302751 & & $1065 \pm 34$ & $\mathrm{fg}$ \\
HD 302759 & & $1682 \pm 94$ & $\mathrm{fg}$ \\
HD 302760 & $+0.33 \pm 0.08$ & & $1164 \pm 45$ & 1342 & $\mathrm{fg}$ \\
HD 302858 & $+0.38 \pm 0.12$ & +0.60 & $1487 \pm 84$ & $\mathrm{fg}$ \\
TYC 8608-1-1 & $-0.04 \pm 0.15$ & +0.45 & $2503 \pm 187$ & $\mathrm{f}$ \\
TYC 8608-25-1 & $-0.29 \pm 0.14$ & -0.42 & $2253 \pm 147$ & 2389 & $\mathrm{~m}$ \\
TYC 8608-69-1 & $-1.82 \pm 0.16$ & -1.18 & $2819 \pm 222$ & 2101 & $\mathrm{~m}$ \\
TYC 8608-153-1 & $+0.87 \pm 0.06$ & +1.89 & $917 \pm 26$ & $\mathrm{~m}$ \\
TYC 8608-193-1 & $-0.89 \pm 0.14$ & +0.70 & $2248 \pm 148$ & 1081 & $\mathrm{fg}$ \\
TYC 8608-213-1 & & & $1940 \pm 110$ & $\mathrm{~m} ?$ \\
TYC 8608-221-1 & & & $1295 \pm 55$ & $\mathrm{~m} ?$ \\
TYC 8608-1503-1 & $-0.90 \pm 0.18$ & -0.10 & $2610 \pm 220$ & $\mathrm{fg}$ \\
\hline
\end{tabular}

P\&M13 - Pecaut \& Mamajek (2013), [m] - confident member, [fg] - foreground star

\subsection{Particular case 1. UW Car problem.}

For this $5 .^{d} 35$ Cepheid according to the Fernie et al. (1995) catalogue $\mathrm{M}_{v}=-3 .^{m} 32$ and $d=$ 1844 pc. According to Anderson (2018), its (V $\left.M_{V}\right)=11 \cdot^{m} 63 \pm 0 \cdot^{m} 20$ and $M_{V}=-3 \cdot{ }^{m} 60 \pm 0 \cdot^{m} 31$. However, according to the GAIA DR18 parallax, $M_{V}$ $=-5 .^{m} 03 \pm 0 .{ }^{m} 23$ and $d=3776 \pm 422 \mathrm{pc}$. Such a large data scatter rises doubts to the UW Car membership in Collinder 220. Although using our distance modulus for the cluster and our $\mathrm{E}_{B-V}$ for the Cepheid, we can derive $\mathrm{M}_{V}=-4 \cdot^{m} 17 \pm 0 \cdot^{m} 71$ and $d=2606 \pm 1008 \mathrm{pc}$ for UW Car.

\subsection{Chemical abundances}

When the atmospheric parameters were derived, we used the VALD oscillator strengths (Kupka et al. 1999) and LTE model atmospheres from Castelli \&
Kurucz (2004) to determine the element abundances. In partucular, we worked on three stars with relatively low projectional rotation velocities: UW Car, CPD $-57^{\circ} 3199$, and HD 90435. As seen from Table 3, two of these objects (except for the Cepheid) are true cluster members. Therefore, the chemical abundances of each object from our list are of interest. Table 4 presents the results of our investigation. It turned our that all these different spectral type stars have an equal iron content, solar-like abundances of $\alpha-$, Fe-group, r- and s-process elements. Our elemental abundances are in good agreement with those derived by Luck \& Lambert (2011). At the same time, the blue giant HD 90435 has a CNO-content close to the solar one, but the cooler Cepheid and $\mathrm{K}$-giant have a deficit of $\mathrm{C}$ and an overabundance of $\mathrm{N}$. 
Table 4: Chemical abundances for single Collinder 220 objects.

\begin{tabular}{|c|c|c|c|c|c|c|c|c|c|c|}
\hline & \multicolumn{4}{|c|}{ UW Car } & \multicolumn{3}{|c|}{76 (HD 90435) } & \multicolumn{3}{|c|}{$69\left(\mathrm{BD}-57^{\circ} 3399\right)$} \\
\hline Element & [El/H] & $\sigma$ & NL & LL11 & {$[\mathrm{El} / \mathrm{H}]$} & $\sigma$ & NL & {$[\mathrm{El} / \mathrm{H}]$} & $\sigma$ & NL \\
\hline $\mathrm{C} \mathrm{I}$ & -0.51 & 0.16 & 7 & -0.17 & & & & -0.34 & 0.20 & 3 \\
\hline C II & & & & & 0.34 & - & 1 & & & \\
\hline N I & 0.55 & 0.07 & 3 & 0.46 & 0.17 & 0.38 & 4 & 0.21 & 0.13 & 2 \\
\hline O I & -0.13 & 0.20 & 3 & 0.18 & 0.19 & - & 1 & 0.13 & 0.07 & 3 \\
\hline $\mathrm{Na} \mathrm{I}$ & 0.26 & 0.10 & 2 & 0.18 & & & & 0.39 & 0.07 & 2 \\
\hline $\mathrm{Mg} \mathrm{I}$ & & & & 0.26 & & & & 0.53 & 0.18 & 2 \\
\hline Mg II & & & & & 0.99 & 0.33 & 2 & & & \\
\hline Al I & 0.23 & 0.19 & 2 & 0.05 & & & & 0.15 & 0.11 & 6 \\
\hline Al II & & & & & 0.76 & - & 1 & & & \\
\hline Si I & 0.04 & 0.14 & 7 & 0.14 & & & & 0.09 & 0.04 & 6 \\
\hline Si II & -0.30 & - & 1 & & -0.17 & 0.09 & 4 & & & \\
\hline S I & -0.20 & - & 1 & & & & & 0.19 & 0.06 & 2 \\
\hline S II & & & & & & & & & & \\
\hline K I & 0.16 & - & 1 & & & & & 0.23 & - & 1 \\
\hline $\mathrm{Ca} \mathrm{I}$ & 0.02 & 0.08 & 4 & 0.09 & & & & -0.10 & 0.06 & 3 \\
\hline Sc II & & & & & & & & 0.19 & 0.12 & 5 \\
\hline Ti I & 0.03 & 0.08 & 17 & 0.19 & & & & -0.10 & 0.17 & 21 \\
\hline Ti II & 0.18 & 0.08 & 2 & & 0.85 & 0.18 & 4 & 0.29 & 0.14 & 4 \\
\hline V I & -0.09 & 0.19 & 4 & & & & & -0.11 & 0.10 & 8 \\
\hline V II & -0.12 & 0.17 & 3 & & & & & -0.13 & 0.08 & 2 \\
\hline Cr I & -0.19 & 0.16 & 16 & 0.05 & & & & -0.15 & 0.17 & 15 \\
\hline Cr II & 0.13 & 0.16 & 16 & & 0.11 & - & 1 & 0.36 & 0.08 & 5 \\
\hline Mn I & -0.15 & 0.12 & 4 & -0.16 & & & & 0.26 & 0.30 & 3 \\
\hline Mn II & & & & & 0.86 & 0.11 & 2 & & & \\
\hline Fe I & 0.09 & 0.10 & 137 & 0.09 & & & & 0.10 & 0.15 & 217 \\
\hline Fe II & 0.09 & 0.11 & 12 & 0.09 & 0.04 & 0.20 & 22 & 0.08 & 0.17 & 19 \\
\hline Co I & -0.22 & 0.13 & 8 & -0.04 & & & & 0.07 & 0.14 & 8 \\
\hline Ni I & -0.07 & 0.15 & 34 & -0.04 & & & & -0.04 & 0.11 & 47 \\
\hline $\mathrm{Ni}$ II & & & & & 0.46 & - & 1 & & & \\
\hline $\mathrm{Cu} \mathrm{I}$ & -0.07 & 0.25 & 4 & & & & & 0.70 & 0.65 & 4 \\
\hline Zn I & -0.09 & - & 1 & & & & & 0.48 & 0.43 & 3 \\
\hline Rb I & 0.17 & - & 1 & & & & & -0.30 & 0.01 & 2 \\
\hline Y II & 0.16 & 0.06 & 4 & 0.17 & & & & 0.36 & 0.22 & 5 \\
\hline Zr II & -0.08 & 0.13 & 2 & & & & & 0.34 & 0.32 & 3 \\
\hline La II & 0.09 & 0.14 & 4 & 0.27 & & & & 0.40 & 0.10 & 5 \\
\hline Ce II & 0.07 & 0.04 & 6 & 0.10 & & & & 0.13 & 0.12 & 5 \\
\hline Pr II & -0.17 & 0.20 & 3 & -0.15 & & & & 0.23 & 0.09 & 4 \\
\hline Nd II & 0.03 & 0.11 & 7 & 0.07 & & & & 0.32 & 0.11 & 7 \\
\hline Sm II & -0.12 & 0.12 & 3 & 0.01 & & & & 0.23 & 0.13 & 3 \\
\hline Eu II & 0.03 & 0.20 & 2 & 0.22 & & & & 0.23 & 0.18 & 3 \\
\hline Gd II & 0.43 & - & 1 & - & & & & 0.39 & - & 1 \\
\hline
\end{tabular}

LL11 - Luck \& Lambert (2011), NL is the number of spectral lines used for the abundance determination.

\section{Summary}

1. According to the derived RV, color-indices, and parallaxes, only 7 of the 18 investigated objects are confident members of Collinder 220. They are HD 90435, CPD - 57 3199 , TYC 8608-1-1, TYC 8608-25-1, TYC 8608-69-1, TYC 8608-1503-1 and UW Car. TYC 8608-193-1, which was assumed to be as a confident member, probably do not belong to the open cluster. Other 11 objects are probably foreground stars.

2. The distances of the confident cluster members, determined from the GAIA DR2 2018 parallaxes, lie in a range of $1900-2800$ pc. The Cepheid distance, which is near $3775 \mathrm{pc}$, is most likely overestimated.

3. Among the confident cluster members, only TYC 8608-25-1 has a high projectional rotation velocity, while for other stars and Cepheid UW Car these estimates lie in a range of $24-40 \mathrm{kms}^{-1}$. The
K-giant CPD $-57^{\circ} 3199$ has a very low value of $\mathrm{v} \sin \mathrm{i}$.

4. We have determined color-excesses $\mathrm{E}_{B-V}$ and reddenings for the majority of objects from the list that allowed us to refine their intrinsic colorindices, especially for the hot stars.

5. Atmospheric parameters of the hot stars were determined by fitting method, while parameters of the Cepheid, K- giant, and blue giant were determined exclusively by the method of atmosphere models.

6. Using $\mathrm{E}_{B-V}, \mathrm{~A}_{V}$, and $R$ values derived by us for confident cluster members, we have determined the mean $\mathrm{A}_{V}=0 .{ }^{m} 20 \pm 0 .{ }^{m} 11$, distance modulus $\mathrm{V}-\mathrm{M}_{V}=11 .^{m} 83 \pm 0 \cdot^{m} 71$, and distance $d=$ $2118 \pm 590$ for the cluster. The Cepheid UW Car has an absolute magnitude of $-4 .^{m} 17 \pm 0 .^{m} 71$ and $d=2606 \pm 1008$ pc.

7. The B-giant HD 90435 is located on the horizontal branch after the cluster's "turn-off" point, while 


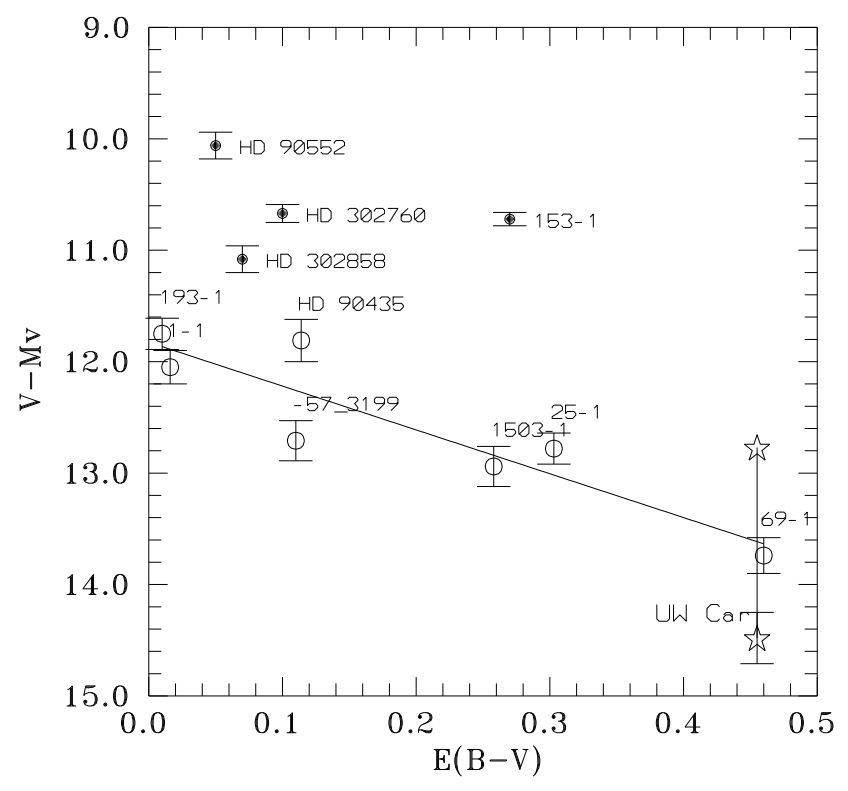

Figure 4: Variable-extinction diagram for possible Collinder 220 members. The symbols represent the same objects as in Fig. 2 and 3.

UW Car and CPD $-57^{\circ} 3199$ are more evolved cool supergiants. Therefore the abundances of carbon, nitrogen, and oxygen in HD 90435 turned out to be close to the solar ones, while there is a deficit of $\mathrm{C}$ and an overabundance of $\mathrm{N}$ and $\mathrm{Na}$ with a solar-like $\mathrm{O}$ abundance for the cool supergiants. This fact indicates that the Cepheid and $\mathrm{CPD}-57^{\circ} 3199$ have already passed through the "first dredge-up" stage.

\section{References}

Anderson, R.I.: 2018, ApJ 861, 36.

Bessell M.S., Castelli F. \& Plez B.: 1998, A\& A, 333, 231.

Cantat-Gaudin, T., Jordi, C., Vallenari, A. et al.: 2018, $A \& A, \mathbf{6 1 8}, 93$.

Castelli, F. \& Kurucz, R.L.: 2004, arXiv: astroph/040508\%.

Chen, X., de Grijs, R., Deng, L.: 2015, MNRAS, 446, 1268.

Coelho, P.R.T.: 2014, MNRAS, 440, 1027.

Dias, W.S., Montero, H., Caetano, T.C., Lepine, J.R.D., Assafin, M., Oliveira, A.F.: 2014, A\&A, 564, 79.

Fernie, J.D., Beattie, B., Evans, N.R., Seager, S.: 1995, IBVS, 4348, 1.

GAIA DR2 Catalogue,: 2018, CDS/ADS Collection of Electronic Ctalogues, 1345, 0.

Gontcharov, G.A.: 2006, AstL 32, 759.

Høg, E., Fabricius, C., Makarov, V.V., et al.: 2000, $A \& A$ 355, 27.

Kharchenko, N.V., Piskunov, A.V., Schilbach, E., Roser, S., Scholtz, R.-D.: 2013, A $\because A$ 558, 53.

Kochanek, C.S., Shappee, B.J., Stanek, K.Z., et al.: 2017, PASP 129, 104502.

Kovtyukh, V.V.: 2007, MNRAS 378, 617.

Kupka, F., Piskunov, N.E., Ryabchikova, T.A., Stempels, H.S., Weiss, W.W.: 1999, A\&A, 138, 119.

Luck, R.E., Lambert, D.L.: 2011, AJ, 142, 136.

Mermilliod, J.C., Mayor, M., Udry, S.: 2008, $A \& A$, 485, 303.

Pecaut, M.J., Mamajek, E.E.: 2013, ApJS, 208, 9.

Segel, M.H., LaPorte, S.J. Porterfield, B.L., Hagen, L.M.Z., Gronwall, C.A.: 2019, AJ 158, 35.

Straizys, V.: 1981, Metal-Deficient Stars, "Mokslas", Vilnius. 